\title{
O Trabalho com o Gênero Textual História em Quadrinhos com Alunos que Possuem DeficiênCia InTelectual ${ }^{1}$ WorkING WITH Comics TEXTUAL GENRE WITH STUDENTS WITH INTELLECTUAL DISABILITIES
}

\author{
Elsa Midori SHIMAZAKI ${ }^{2}$ \\ Viviane Gislaine Caetano AUADA ${ }^{3}$ \\ Renilson José MENEGASSI ${ }^{4}$ \\ Nerli Nonato Ribeiro MORI ${ }^{5}$
}

\begin{abstract}
RESUMO: a instituiçâo escolar é o espaço socialmente estabelecido para a mediação dos conceitos científicos que organizam e orientam a sociedade. Dentre os conceitos científicos que precisam ser mediados, estão os relativos ao gênero textual História em Quadrinhos (HQ), tipicamente trabalhado nas escolas e, também, de circulação cotidiana. Assim, este texto objetiva relatar, analisar e refletir sobre as estratégias desenvolvidas para que as pessoas com deficiência intelectual se apropriem dos conceitos científicos presentes nas histórias em quadrinhos, a partir do princípio de que é responsabilidade escolar trabalhar com o desenvolvimento dos conceitos científicos, inclusive aqueles relacionados a determinado gênero textual de circulaçáo social. Trata-se de uma pesquisaação desenvolvida com quatro alunos de uma escola pública do Noroeste do Paraná, que atende na modalidade Educação de Jovens e Adultos (EJA) de Ensino Fundamental e Ensino Médio. Para alcançar o objetivo proposto, na fase inicial da pesquisa, identificaram-se os conhecimentos prévios dos sujeitos, que serviram de respaldo para planejar as intervençóes significativas ao grupo.Após a intervenção, constatou-se que os sujeitos se apropriaram do conjunto de conceitos científicos que constituem o gênero textual História em Quadrinhos e melhoraram a qualidade da compreensão e interpretação das HQs e, por conseguinte, suas possibilidades de atuaçáo social.
\end{abstract}

PALAVRAS-CHAVE: Letramento. Gêneros textuais. História em quadrinhos. Jovens e adultos. Educação Especial.

\begin{abstract}
School is a social space established for the mediation of scientific concepts that organize and guide society. Among the scientific concepts that should be mediated are those related to the Comics textual genre, which is normally exercised in the classroom and of daily circulation. Thus, this text aims to report, analyze and reflect on the strategies developed for people with intellectual disabilities to appropriate scientific concepts present in the comic books, based on the principle that it is the responsibility of the school to work with the development of scientific concepts, including those related to a specific textual genre of social circulation. It is an action research developed with four students from a public school in the Northwest of Paraná state, Brazil, which incorporates the Youth and Adult Education (called EJA) modality at Elementary and High School level. To reach the proposed objective, in the initial phase of the research, background knowledge of the subjects was identified, which served as support to plan the significant interventions for the group. After the intervention, it was verified that the subjects appropriated the set of scientific concepts that constitute the Comics textual genre and improved the quality of their understanding and interpretation of the Comics and, consequently, their possibilities of social interaction.
\end{abstract}

KEYWORDS: Literacy. Textual genres. Comics. Young people and adults. Special Education.

\footnotetext{
${ }^{1}$ http://dx.doi.org/10.1590/S1413-65382418000100010

${ }^{2}$ Doutora em Educação pela Universidade de São Paulo. Docente do Departamento de Teoria e Prática da Educação e do Programa de Pós-Graduação em Educação. Universidade Estadual de Maringá, Maringá - PR, Brasil. emshimazaki@uem.br.

${ }^{3}$ Doutoranda do Programa de Pós-Graduação em Educação. Universidade Estadual de Maringá, Maringá - PR, Brasil. vigcaetano@hotmail.com.

${ }^{4}$ Doutor em Letras pela Universidade Estadual Júlio de Mesquita Filho. Docente do Departamento de Teorias Linguísticas e Literárias e do Programa de Pós-Graduação em Letras. Universidade Estadual de Maringá, Maringá - PR, Brasil. renilson@wnet.com.br.

5 Doutora em Psicologia Escolar e do Desenvolvimento pela Universidade de São Paulo. Docente do Departamento de Teoria e Prática da Educação e do Programa de Pós-Graduação em Educação. Universidade Estadual de Maringá, Maringá - PR, Brasil. nnrmori@uem.br.
} 


\section{INTRODUÇÃo}

Os gêneros textuais são considerados bens culturais que orientam e determinam as relações interpessoais (MARCUSCHI, 2005), pois, todas as vezes que há a comunicação da atividade psíquica por meio da linguagem verbal, seja ela oral ou escrita, recorre-se a um gênero textual para materializá-la em um corpo social determinado. Assim, a partir do pressuposto de que cada gênero textual cumpre adequadamente uma finalidade de interaçấo social, considera-se a necessidade de apropriaçáo de um conjunto de gêneros textuais para que se estabeleçam, cotidianamente, as relaçôes interpessoais que a convivência em sociedade impóe, uma vez que são pelos gêneros que o homem se comunica.

Ao tratar-e de pessoas com deficiência intelectual, além das leis que asseguram a inclusão nos diferentes espaços que constituem e integram a sociedade, há documentos oficiais que enfatizam a necessidade de se trabalhar sistematicamente com gêneros textuais no campo escolar, com essa parcela da populaçáo, como é o caso dos Parâmetros Curriculares Nacionais para o Ensino Médio (BRASIL, 2000). Considera-se que o trabalho escolar deve primar pela formação de alunos leitores e produtores dos gêneros em diferentes contextos sociais, ao qual incluímos, também, alunos com essa deficiência.

Além disso, ao considerar-se que o entretenimento faz parte de inúmeros espaços sociais, pois é de fundamental importância para uma vida saudável, e sendo a História em Quadrinhos (HQ) um gênero textual que cumpre essa função na sociedade, partiu-se do princípio de que é um gênero que precisa de ensino sistematizado junto aos alunos com deficiência intelectual, para que aprendam a lidar com uma manifestaçấo de linguagem comum ao seu entorno social.

Diante do exposto, este texto objetiva relatar, analisar e refletir sobre as estratégias desenvolvidas para que alunos com deficiência intelectual se apropriem dos conceitos científicos presentes em HQ, partindo-se do princípio de que é responsabilidade da escola trabalhar com o desenvolvimento dos conceitos científicos, inclusive aqueles relacionados a determinado gênero textual. Trata-se de uma pesquisa-ação desenvolvida com 4 jovens e adultos com diagnóstico de deficiência intelectual em uma escola do Noroeste paranaense, que atende na modalidade Educaçáo de Jovens e Adultos (EJA) de Ensino Fundamental e Ensino Médio. Os dados foram coletados a partir de sessóes videografadas, do plano de aula, das atividades desenvolvidas pelos alunos, os quais foram analisados qualitativamente.

\section{CONCEITOS PRINCIPAIS}

A Associação Americana de Deficiência Intelectual e do Desenvolvimento (AAIDD), em sua definição mais recente, caracteriza a deficiência intelectual como uma

[...] incapacidade caracterizada por limitaçóes significativas tanto no funcionamento intelectual (raciocínio, aprendizado, resolução de problemas), quanto no comportamento adaptativo, que cobre uma gama de habilidades sociais e práticas do dia a dia. Esta deficiência se origina antes da idade de 18 anos (SCHALOCK et al., 2010, p. 6).

Por sua vez, as pesquisas de Góes (2002), Shimazaki (2006), Auada (2015), Padilha (2017) mostram que, embora haja limitaçôes no funcionamento intelectual, as pessoas com 
deficiência intelectual possuem as mesmas possibilidades de desenvolvimento que as demais pessoas, necessitando apenas de algumas condiçóes peculiares, o que não elimina o trabalho com conceitos científicos, mas, sim, propóe metodologias e recursos diferenciados para a mediação docente, considerando-se, sempre, as idiossincrasias de cada sujeito. Nesse sentido, a apropriação dos bens culturais elaborados e organizados socialmente efetiva-se da mesma forma, ou seja, por meio da formação de conceitos científicos.

Segundo Vygotsky (2000), a (re)elaboração dos conceitos efetiva-se nas atividades sociais e escolares desde que sejam significativas e proporcionem a participação efetiva do sujeito em práticas sociais. Nesse processo, sáo requisitos a experiência pessoal do indivíduo e os conhecimentos mediados em sala de aula, que promovem o desenvolvimento dos conceitos espontâneos e os não-espontâneos, ou seja, conceitos cotidianos e científicos, respectivamente.

A esse respeito, o autor afirma que os conceitos espontâneos e os não-espontâneos, ainda que se (re)organizem motivados por processos distintos, não estão em conflito; pelo contrário, são interdependentes e fazem parte do mesmo processo, a formação de conceitos. Assim sendo, “[...] a ausência de um sistema é a diferença psicológica principal que distingue os conceitos espontâneos dos conceitos científicos” (VYGOTSKY, 1987, p. 99).

Cumpre ressaltar que o percurso do processo de abstração e de generalização dos conceitos científicos é descendente, pois se originam nas definiçóes conceituais em sala de aula e, na maioria das vezes, são seguidas de atividades escolares, aplicaçóes não espontâneas para $a$ posteriori incorporarem-se às experiências extra-escolares de forma consciente.

No desenvolvimento dos conceitos espontâneos, o processo de abstração e de generalização é ascendente, pois o conceito é experienciado nas atividades extra-classe sem que haja, neste momento, a consciência de sua definição conceitual, a qual só ascenderá posteriormente. Nesse sentido, Padilha (2017) discute as possibilidades de formação conceitual pelas pessoas que possuem deficiência intelectual.

As práticas pedagógicas organizadas e sistematizadas, com objetivos claramente definidos, com estratégias selecionadas e realizadas por meio do material adequado constituem as possibilidades de transformar a escola no lugar privilegiado para que os alunos, com a mediaçáo dos professores, caminhem do conhecimento espontâneo, genérico, confuso, sincrético para o conhecimento consciente, não cotidiano (PADILHA, 2017, p. 11).

Dentre os conceitos científicos mediados pela escola, há os conceitos relativos aos gêneros textuais e à cada especificidade de gênero. $\mathrm{O}$ trabalho com gêneros textuais na instituição escolar está respaldado em documentos oficiais, como é o caso dos Parâmetros Curriculares Nacionais para o Ensino Médio (BRASIL, 2000), ao considerar que a escola deve primar pela formação de alunos leitores e produtores dos gêneros em diferentes contextos sociais.

No entanto, nem sempre as terminologias gênero textual, tipologia textual e suporte textual, imprescindíveis ao trabalho sistematizado com os gêneros que circulam na sociedade, são depreendidas em suas definiçóes científicas no ambiente escolar. Urge, portanto, a necessidade de conhecermos a diferença entre eles. Marcuschi (2005) define gêneros textuais como "[...] textos materializados que encontramos em nossa vida diária e que apresentam características sócio-comunicativas definidas por conteúdos, propriedades funcionais, estilo e composição 
característica" (MARCUSCHI, 2005, p. 22-23). Para o autor, diante da multiplicidade de gêneros existentes, devemos ter clareza da finalidade do gênero utilizado, por exemplo: para encontrar um endereço desconhecido, o que devo consultar? Para conversar com um parente que está longe, como devo proceder? Para criar um clima de descontração com os amigos, como agir? As respostas a esses questionamentos nos conduzem a diferentes gêneros, tais como: mapa, telefonema, carta, e-mail, piada, dentre outros. Assim sendo, constatam-se diferentes situações sociais nas quais temos diferentes finalidades e, portanto, recorremos a diferentes gêneros textuais. Nesse sentido, Marcuschi (2005, p. 19)acrescenta que

[...] os gêneros textuais são fenômenos históricos profundamente vinculados à vida cultural e
social. Fruto de trabalho coletivo, os gêneros contribuem para ordenar e estabilizar as atividades
comunicativas do dia-a-dia. São entidades sócio-discursivas e formas de ação social incontorná-
veis em qualquer situação comunicativa.

A tipologia textual é uma "[...] sequência teoricamente definida pela natureza linguística de sua composição, aspectos lexicais, sintáticos, tempos verbais, relaçóes lógicas” (MARCUSCHI, 2005, p. 22), definidas em cinco tipos: narração, descrição, exposição, argumentação e injunção. De acordo com o autor, cada tipologia textual possui especificidades que as distinguem entre si, assim caracterizadas:

- Tipologia narrativa refere-se ao relato de acontecimentos, reais ou fictícios. Esses relatos são feitos por meio de um narrador. Há a participação de personagens, com tempo e espaço definidos.

- $\quad$ Tipologia descritiva refere-se à caracterização de uma pessoa, objeto, ambiente ou paisagem. Consiste em um relato verbal do observado. Na tipologia descritiva, há de considerarem-se dois aspectos fundamentais quando, por exemplo, o foco é a descrição de uma pessoa: as características físicas, que consistem na descrição da aparência externa; e as características psicológicas, que consistem na descrição do modo de ser e de agir da pessoa descrita.

- Tipologia expositiva prima por sequências explicativas com o intuito de explanar ainda mais um tema, ou seja, propiciar ao leitor conhecimento e compreensão de determinado assunto.

- Tipologia argumentativa defende um ponto de vista acerca de um assunto, ideia ou conceito. Tem o objetivo de, por meio da exposição de fatos, de ideias e de conceitos, chegar a conclusóes lógicas e verossímeis que possam convencer alguém sobre um determinado posicionamento ou opinião.

- Tipologia injuntiva refere-se às sequências explicativas, com a intenção de que o interlocutor pratique uma determinada ação, em uma sequência certa. Apresenta o passo a passo dessa ação de forma clara e concisa. Um bom exemplo são as receitas e as regras de jogo que demonstram, passo a passo, como realizar ação para que se chegue ao resultado esperado.

Cumpre frisar que, em um gênero textual, há o predomínio de uma tipologia textual, mas ela não é a única tipologia possível/presente do gênero. Por exemplo, nos gêneros textuais 
HQ, tirinhas de quadrinhos, contos, há o predomínio da tipologia narrativa; contudo, podem também estar presentes as tipologias descritiva e expositiva. Desse modo, quando os componentes curriculares contemplarem as tipologias expostas, o professor pode lançar mão de vários gêneros textuais como instrumento de ensino, desde que sejam do mesmo campo social. No entanto, conhecer os gêneros textuais e as tipologias que o compóem não é o suficiente para que a aprendizagem se efetive. É necessário um trabalho maior sobre eles.

As pesquisas de Bakhtin (2000), Chartier (2003) e Marchuschi (2005) são unânimes ao afirmar que o material no qual o gênero textual está impresso, concebido como suporte, é primordial para subsidiar a compreensão e a estruturação do texto, pois é uma marca social muito bem definida. Nesse sentido, podemos classificar como suporte dos gêneros textuais uma matéria específica com características próprias em que os gêneros são visualizados, por exemplo: o gênero textual Notícia impressa tem como o suporte o jornal; uma letra de música tem como suporte o encarte do CD; uma HQ tem por suporte, naturalmente, um gibi, uma revista em quadrinhos. Assim, "[...] cada forma, cada suporte, cada estrutura da transmissão e da recepção do escrito afeta profundamente seus possíveis usos e interpretaçóes” (CHARTIER, 2003, p. 44-45).

Para Chartier, forma, suporte e texto estão intrinsecamente ligados para a construção dos sentidos, pois " [...] a significação, ou melhor, as significaçôes, histórica e socialmente diferenciadas de um texto, qualquer que seja não podem ser separadas das modalidades materiais que o dão a ler a seus leitores" (CHARTIER, 2003, p. 46). Os suportes, portanto, são veículos para que os gêneros textuais se materializem e circulem na sociedade. É um conceito científico que precisa ser trabalhado com os alunos.

Diante do exposto, levantamos uma questão pedagógica: como podemos organizar e sistematizar o ensino dos gêneros textuais diante desta multiplicidade de conceitos fundamentais para seu uso efetivo? Para isso, buscamos resposta na sequência didática proposta por Dolz, Noverraz e Schneuwly (2004), que consiste em uma proposta metodológica (Figura 1) que permite ao aluno refletir conscientemente sobre cada aspeto fundante do gênero.

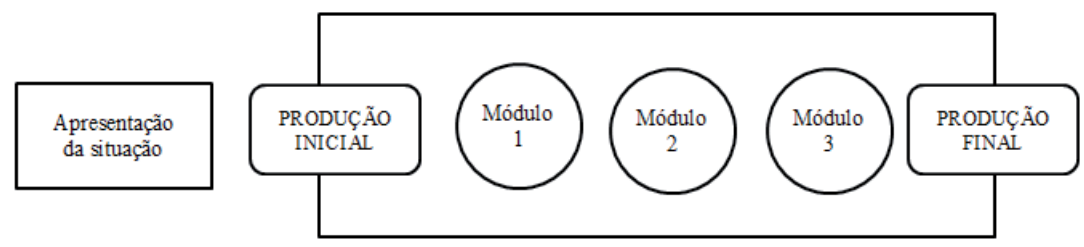

Figura 1 - Esquema da sequência didática

Fonte: Dolz, Noverraz e Schneuwly (2004, p. 98).

Segundo os autores, essa proposta de ensino com gêneros textuais envolve quatro etapas distintas que, em consonância, ao final da sequência, possibilitam ao aluno a visão do gênero em sua totalidade, bem como de todas as especificidades que o compóe, habilitando-o possivelmente como leitor e produtor. Dessa forma, a primeira etapa consiste na Apresentação da Situação, em que se estabelece qual gênero textual é trabalhado; se será produzido na mo- 
dalidade oral ou escrita da língua; as suas condiçóes de produção; bem como os conteúdos que serão trabalhados, intrinsicamente ligados ao gênero escolhido, apresentando alguns de seus exemplares ou ainda solicitando pesquisas em sala sobre ele.

A segunda etapa consiste na Produção Inicial, ou seja, a primeira escrita do gênero pelo aluno, efetivando-se de forma individual ou coletiva - etapa fundamental, pois serve de base para a organização do trabalho pedagógico.

A terceira etapa consiste na organização por meio de Módulos. Não há um número determinado de módulos; assim, eles são constituídos para suprir as lacunas apresentadas na produção inicial, bem como as que podem surgir ao longo do processo.

A quarta e última etapa consiste na Produção Final, momento que os alunos produzirão o gênero textual, contemplando todos os conhecimentos que foram apropriados durante o estudo do gênero. Esta proposta é adequada a todos os alunos com ou sem deficiência.

\section{Metodologia da Pesquisa}

A presente pesquisa investigou o processo de apropriação conceitos científicos relativos ao gênero textual História em Quadrinhos (HQ), em atividades sistematizadas na instituição escolar. Para seu desenvolvimento, recorremos à pesquisa-açáo, pois a intervenção para o ensino do gênero textual escolhido efetivou-se de forma sistematizada a possibilitar discussóes, bem como aprimorar a prática pedagógica em um movimento reflexivo de nossa parte. Nesse sentido, Tripp (2005, p. 445-446) define a pesquisa-ação como "[...] qualquer processo que siga um ciclo no qual se aprimora a prática pela oscilação sistemática entre o agir no campo da prática e investigar a respeito dela”.

\subsection{LOCAL DA PESQUISA}

A pesquisa de campo foi desenvolvida em uma unidade do Centro Estadual de Educação Básica para Jovens e Adultos (CEEBJA) de uma cidade do Norte do Paraná. A instituição oferece atendimento exclusivo para jovens e adultos desde 7 de maio de 1985.

Atualmente, o CEEBJA atende6, nos períodos matutino, vespertino e noturno, 3.017 alunos no Ensino Fundamental e no Ensino Médio. Desse total, 35 alunos do Ensino Fundamental possuem DI, e 17 apresentam outras deficiências. No Ensino Médio, 29 são caracterizados como DI, quatro com outras deficiências. Destacamos que, no vespertino, período em que foi realizada a pesquisa, estavam matriculados oito alunos com DI.

\subsection{SujeITOS DA PESQUisa}

Participaram da pesquisa quatro sujeitos, assim caracterizados: a) matriculados nas séries finais da Educação Básica, na modalidade EJA; b) já se apropriaram do sistema de escrita alfabética; c) identificados com deficiência intelectual. Os dados aqui apresentados foram extraídos dos cadastros e das avaliaçóes psicopedagógicas dos alunos, cedidos pela secretaria da instituição de ensino.

${ }^{6}$ Dados fornecidos pela secretaria da instituição de ensino, referentes aos três turnos de atendimento. 
O sujeito 1, do sexo masculino, tem 30 anos de idade e possui deficiência intelectual, sendo sua etiologia Síndrome de Down. O sujeito 2, do sexo feminino, tem 28 anos de idade e possui deficiência intelectual e neuro-motora, porém não teve a etiologia de sua deficiência definida. O sujeito 3, do sexo masculino, tem 26 anos de idade, possui deficiência intelectual; no entanto, não teve a etiologia de sua deficiência definida. $\mathrm{O}$ sujeito 4 , do sexo masculino, tem 31 anos de idade e possui deficiência intelectual, sendo a etiologia Traumatismo Craneoencefálico severo.

\subsection{Procedimentos}

Para o desenvolvimento da pesquisa, reunimo-nos em uma das salas da instituição escolar, em dias e horários predeterminados. No primeiro momento, fizemos a leitura com interpretação escrita de uma história em quadrinhos de Maurício de Sousa para verificar o conhecimento espontâneo dos sujeitos em relação ao gênero textual, por meio de questóes específicas. No segundo momento, problematizamos o assunto por meio de discussão, no intuito de instigar os sujeitos a buscar respostas para os questionamentos. No terceiro momento, desenvolvemos atividades sistematizadas para compreensão e interpretação das condiçóes de produção, do tema e do enredo da HQ. Para tanto, recorremos às histórias de Maurício de Sousa e, após a leitura, fizemos a interpretação direcionada, também por meio de alguns questionamentos.

\section{APRESENTAÇÁO E DisCUSSÃo dos RESULTADOS}

A intervenção para o ensino da HQ foi elaborada seguindo a proposta de Dolz, Noverraz e Schneuwly (2004). Nessa perspectiva, o trabalho configurou-se na seguinte sequência: Apresentação da situação, Produção inicial, Módulo I, Módulo II, Módulo III e Produção final.

Diante das limitaçóes deste texto, optamos por detalhar e discutir os resultados das atividades desenvolvidas no Módulo I. A escolha respaldou-se no fato de esse módulo ser a base para leitura e produção não só da $\mathrm{HQ}$, mas também de outros gêneros da tipologia narrativa, pois nele foram mediados conceitos estruturais dessa tipologia textual específica.

Assim, no primeiro momento, fizemos a leitura com interpretação escrita de uma história em quadrinhos de Maurício de Sousa para verificar o conhecimento espontâneo dos sujeitos em relação ao assunto, por meio de questóes específicas (Caixa de texto 1). 
a) Quem produziu a história em quadrinhos? (Qual é o autor da HQ, de que lugar ele fala. Fala como criança, Jovem, adulto ou idoso?)

b) Para quem se produziu a história em quadrinhos? (Qual o público a quem essa história foi pensada?)

c) Onde circula o gênero História em Quadrinhos? (Quais ambientes sociais podemos encontrar essas histórias?)

d) Qual tema a história em quadrinhos abordou?

e) Qual é a finalidade do autor ao escrever sobre esse tema?

f) Quem são as personagens da história?

g) Onde se passa a história?

h) Quando se passa a história?

i) O que aconteceu na história?

j) Qual foi o problema que aconteceu e ocasionou o conflito da história em quadrinhos?

k) Como o problema foi resolvido? Qual foi o desfecho/final da história?

1) Você esperava por esse desfecho/final? Por quê?

m) Qual desfecho/final você imaginou/pensou para a história? Mencione-o.

n) Se você estivesse no lugar do autor, qual desfecho/final você daria para a história?

Caixa de texto 1- Questôes para avaliação de conhecimentos espontâneos da leitura da HQ Fonte: Elaboração própria.

No segundo momento do Módulo I, oportunizamos uma discussão a fim de problematizar o assunto, no intuito de instigar os sujeitos a buscar respostas para os questionamentos, tornando, dessa forma, a intervenção mais significativa e prazerosa, também por meio de questionamentos (Caixa de texto 2).
a) Quem já ouviu falar em histórias em quadrinhos?
b) O que é uma história em quadrinhos?
c) O que tem em uma história em quadrinhos?
d) Como eu sei que é uma história em quadrinhos?
e) Onde podemos encontrar as histórias em quadrinhos?
f) Quem escreve as histórias em quadrinhos?
g) Por que as pessoas escrevem as histórias em quadrinhos? Com qual finalidade?
h) Qual é o tema das histórias em quadrinhos?
i) Quem lê as histórias em quadrinhos?
j) Onde vocês leem histórias em quadrinhos?
k) Por que vocês leem histórias em quadrinhos?
1) Quais histórias em quadrinhos vocês conhecem?
m) Quais personagens das histórias em quadrinhos vocês conhecem?
n) O que significa a sigla HQ?

Caixa de texto 2 - Questóes para a problematização da discussão sobre HQ

Fonte: Elaboração própria.

No terceiro momento do Módulo I, desenvolvemos atividades sistematizadas para compreensão e interpretação das condiçôes de produção, do tema e do enredo da HQ. Para tanto, recorremos às histórias de Maurício de Sousa e, após a leitura, fizemos a interpretação direcionada por meio desses questionamentos (Caixa de texto 3). 

a) Quem produziu a história em quadrinhos?
b) Para quem se produziu a história em quadrinhos?
c) Onde circula o gênero História em Quadrinhos?
d) Qual tema a história em quadrinhos abordou?
e) Qual é a finalidade do autor ao escrever sobre esse tema?
f) Quem são as personagens da história?
g) Onde se passa a história?
h) Quando se passa a história?
i) O que aconteceu na história?
j) Qual foi o problema que aconteceu e ocasionou o conflito da história em quadrinhos?
k) Como o problema foi resolvido? Qual foi o desfecho/final da história?
l) Você esperava por esse desfecho/final? Por quê?
m) Qual desfecho/final você imaginou/pensou para a história? Mencione-o.
n) Se você estivesse no lugar do autor, qual desfecho/final você daria para a história?

Caixa de texto 3-Questóes de compreensão e de interpretação sobre as $\mathrm{HQ}$ Fonte: Elaboração própria.

Compreender as condições de produção das HQ, expressas nas perguntas “a”, "b” e "c", auxilia os alunos na interpretação do tema e do enredo, questóes expressas nas perguntas "d" e "e". Da mesma forma que contribuem para a interpretação do enredo das histórias, contida nas perguntas "h", “i”, “j” e "k". Ressaltamos que esse conjunto de perguntas instrumentaliza o aluno a repensar com criatividade e, ao mesmo tempo, originalidade as partes da história, apontadas nas perguntas "l", "m" e "n", corroborando a produção das suas próprias histórias no módulo final.

O Módulo I foi organizado e trabalhado com intuito de mediar os conceitos científicos de: personagem, tempo, espaço, clímax, desfecho, tema, finalidade, sigla $\mathrm{HQ}$, autoria e público a quem se destinam essas produçóes, bem como sobre onde é possível encontrar essas produçóes na nossa sociedade.

A primeira atividade teve os sujeitos 2 e 4 realizando a leitura da história em quadrinhos Cascão em: escrevendo o quê?? (Figura 2), de Maurício de Sousa, em voz alta. Cada uma das personagens foi representado por um dos participantes: o sujeito 2 representou a Mônica, e o sujeito 4, o Cascão, e nós narramos a história. 


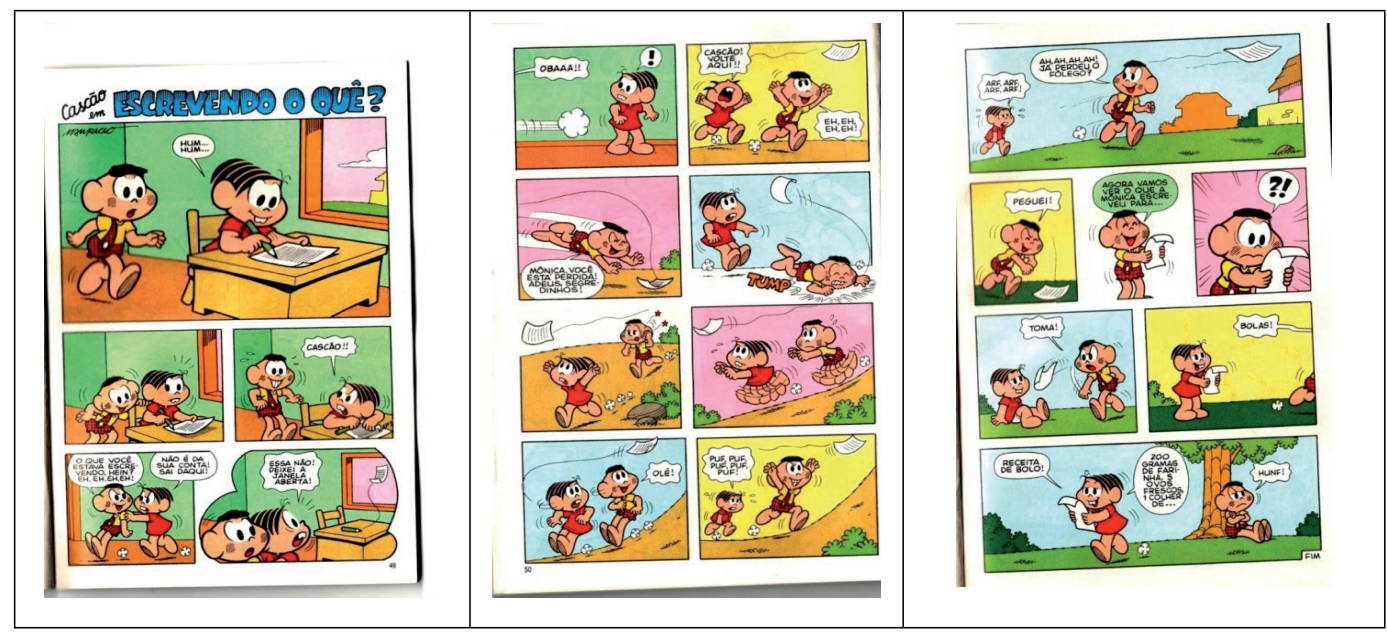

Figura 2 - História em quadrinhos Cascão em: escrevendo o quê?

Fonte: Almanaque da Mônica (2014, p. 49-51).

A atividade foi desenvolvida na tentativa de verificar os conhecimentos espontâneos que os alunos possuíam sobre as condições de produção, do tema e do enredo das histórias em quadrinhos. Para ser desenvolvida, líamos as perguntas e questionávamos se eles a haviam compreendido. Posteriormente, solicitávamos que os sujeitos folheassem as histórias e relessem-nas, se fosse o caso, para depreenderem as respostas e, então, registrá-las de forma individual. Esse procedimento deve-se à condiçâo de deficiência intelectual diagnosticada nos participantes. Após a leitura de cada pergunta, era dado um tempo para que os sujeitos as respondessem na modalidade escrita da língua.

A Caixa de texto 4 apresenta as respostas sobre as condiçóes de produção emitidas pelos sujeitos 1, 2 e 4 . O sujeito 3 precisou sair mais cedo da aula e náo respondeu às perguntas iniciais do questionário que levou dois dias para ser concluído. Sua participação se efetivou a partir da pergunta "f". 


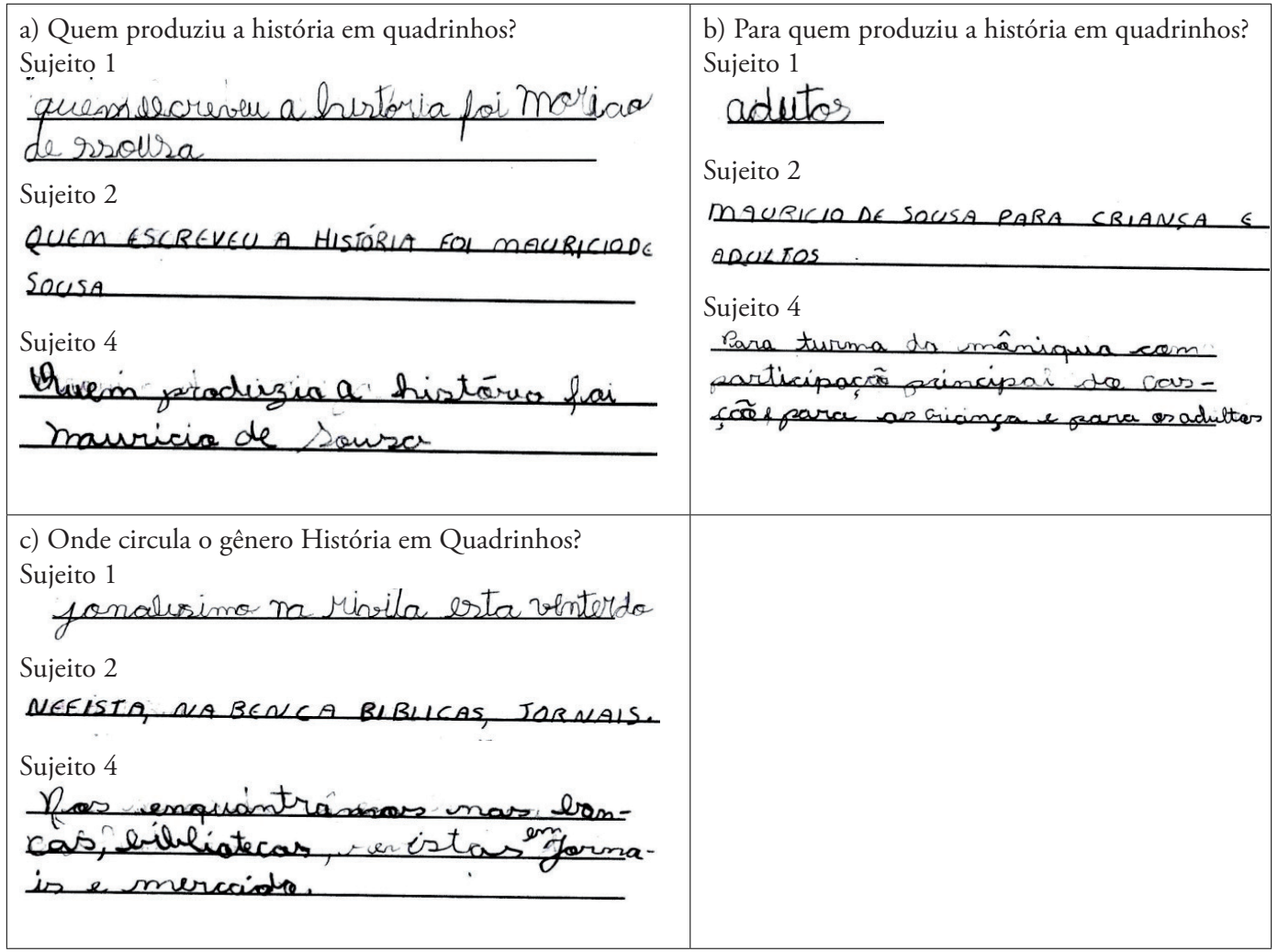

Caixa de texto 4 - Respostas das questões sobre as condições de produção da HQ

Fonte: Elaboração própria a partir das questóes elaboradas e respostas dos alunos. ${ }^{7}$

As respostas mostram que os alunos já tinham um bom nível de letramento sobre as condiçóes de produção do gênero textual em questão, pois responderam às perguntas, depreendendo quem é o autor da história, para quem ele a produziu e onde podemos encontrá-la em nossa vida cotidiana, conceitos espontâneos avaliados.

A seguir, na Caixa de texto 5 , apresentamos as respostas emitidas sobre a temática da história trabalhada com os sujeitos 1,2 e 4 .

${ }^{7}$ As produções escritas dos sujeitos foram tratadas de modo que as identidades dos participantes fossem resguardadas. 


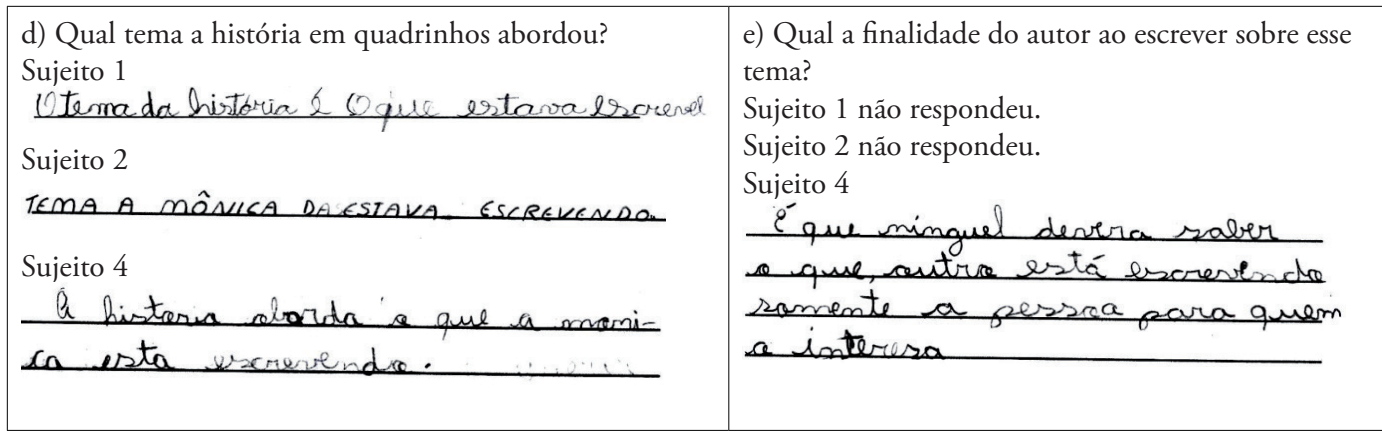

Caixa de texto 5 - Respostas sobre o tema da HQ

Fonte: Elaboração própria a partir das questôes elaboradas e respostas dos alunos.

Ao analisarmos as respostas produzidas pelos sujeitos sobre a temática da história, constatamos que eles não a reconheceram, pois afirmaram ser o que a Mônica estava escrevendo. Logo, inferimos que eles estavam falando da curiosidade; contudo, a curiosidade é o assunto, é o mais geral. O tema é mais específico e requer uma leitura mais aprofundada. Nesse caso, consistiu na curiosidade pela vida alheia, isto é, na curiosidade do Cascão pelo escrito da Mônica, uma vez que o Cascão ficou obstinado em descobrir o que sua colega estava escrevendo e, ao final, se frustrou com o que leu; mesmo assim, sua curiosidade foi sanada. É certo que o conceito científico de tema da HQ mostrou-se em fase inicial de apropriação, sendo necessário um trabalho específico sobre ele.

Em relação à questão "e", os sujeitos 1 e 2 não conseguiram responder sobre a finalidade do autor ao escrever sobre esse tema. Somente o sujeito 4 conseguiu respondê-la, ao afirmar: É que ninguém deverá saber o que o outro está escrevendo, somente a pessoa para quem o interessa. Esse é outro conceito da HQ que carece de um trabalho melhor. Na realidade, tanto o tema quanto a finalidade são conceitos científicos mais difíceis de trabalho com os alunos, sejam eles com ou sem deficiência.

A Caixa de texto 6 demonstra as respostas referentes ao enredo da história em quadrinhos. 


\begin{tabular}{|c|c|}
\hline 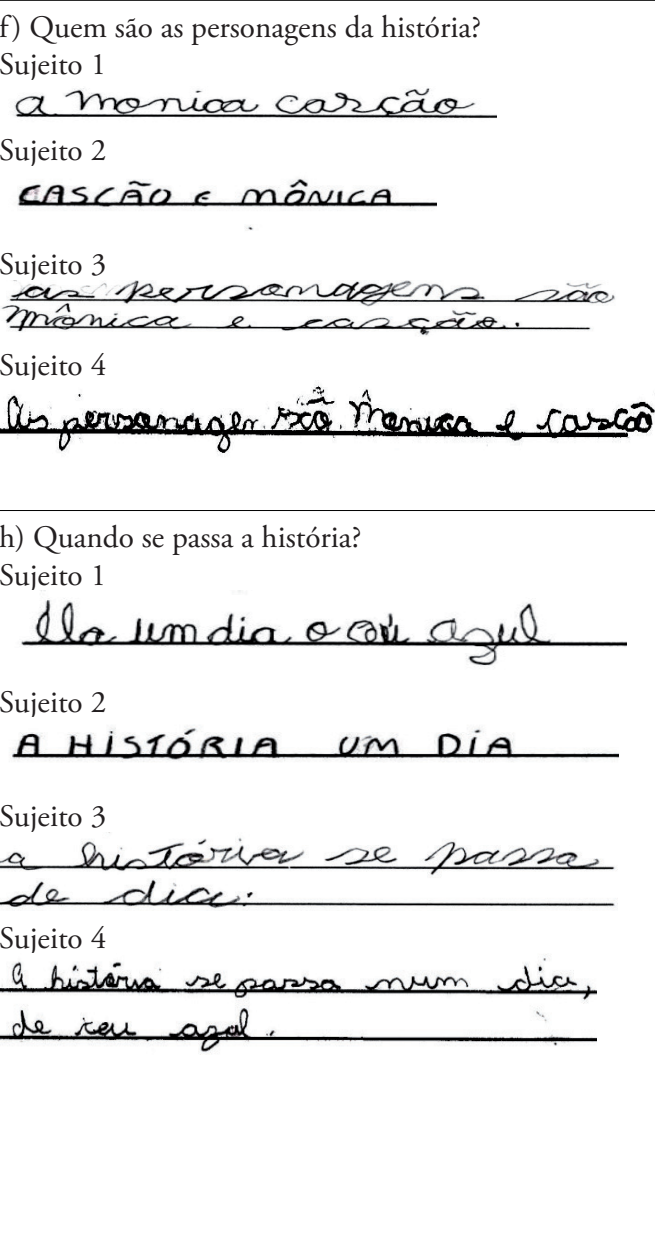 & 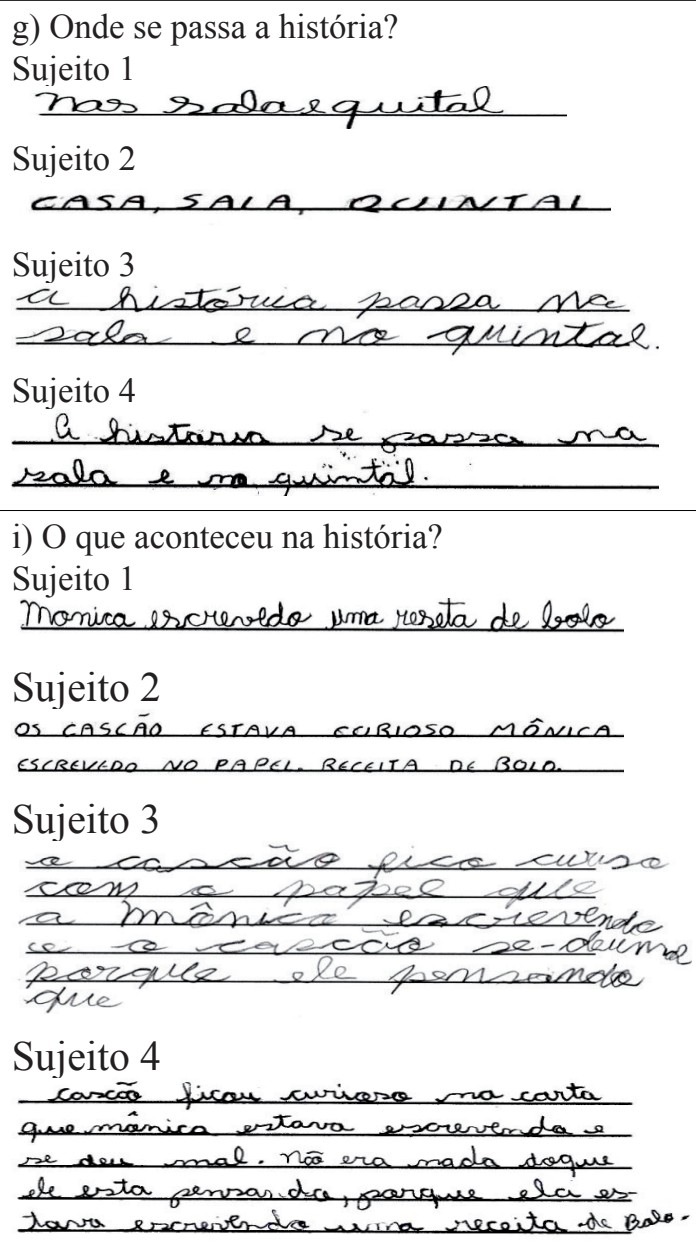 \\
\hline
\end{tabular}




\begin{tabular}{|c|c|}
\hline $\begin{array}{l}\text { j) Qual foi o problema que aconteceu e ocasionou o } \\
\text { conflito da história em quadrinhos? } \\
\text { Sujeito } 1 \\
\text { Olndgadia do coscão } \\
\text { Sujeito } 2 \\
\text { A IANEIA }\end{array}$ & $\begin{array}{l}\text { k) Como o problema foi resolvido? Qual foi o } \\
\text { desfecho/final da história? } \\
\text { Sujeito } 1 \\
\text { Oresita } \\
\text { Sujeito } 2 \\
\text { A RECELIA De Bere. }\end{array}$ \\
\hline 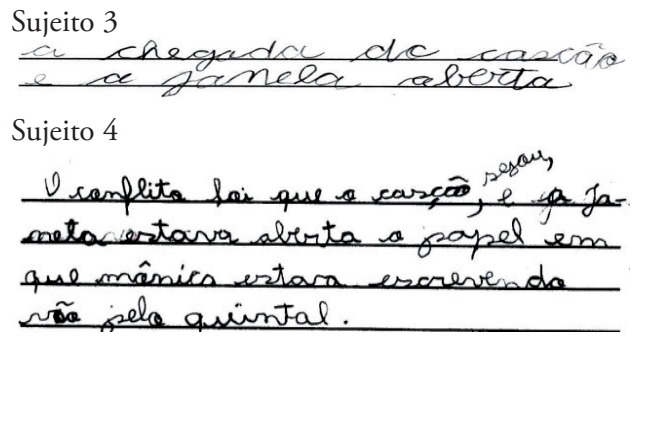 & 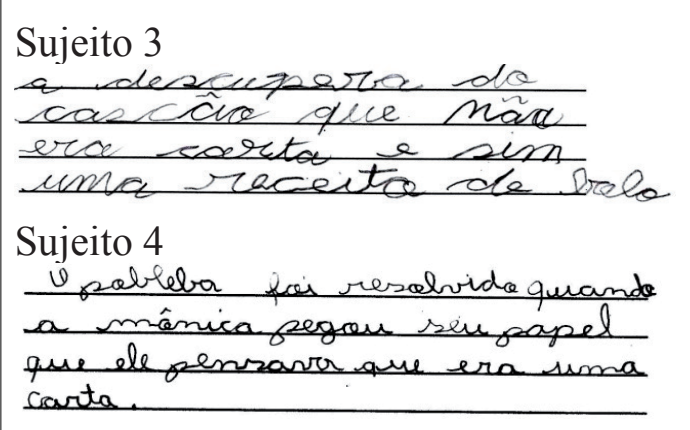 \\
\hline 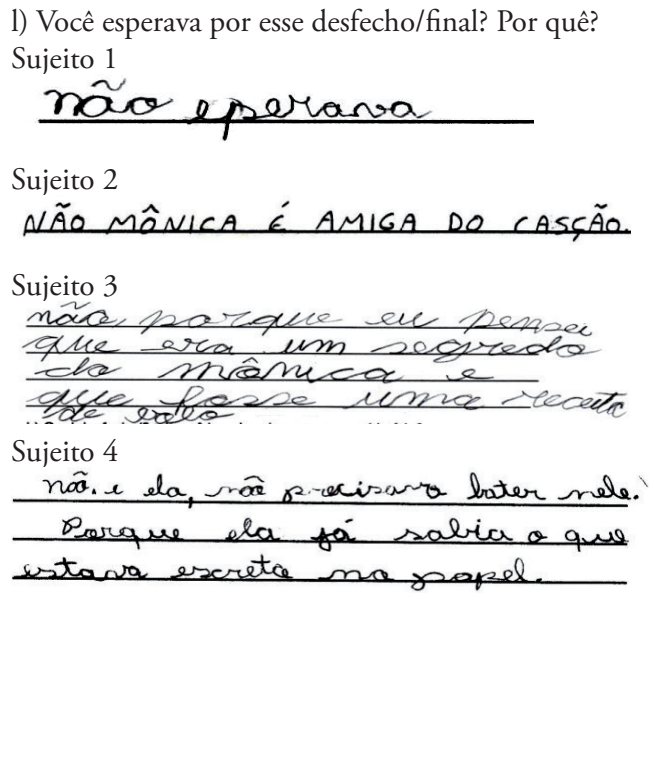 & 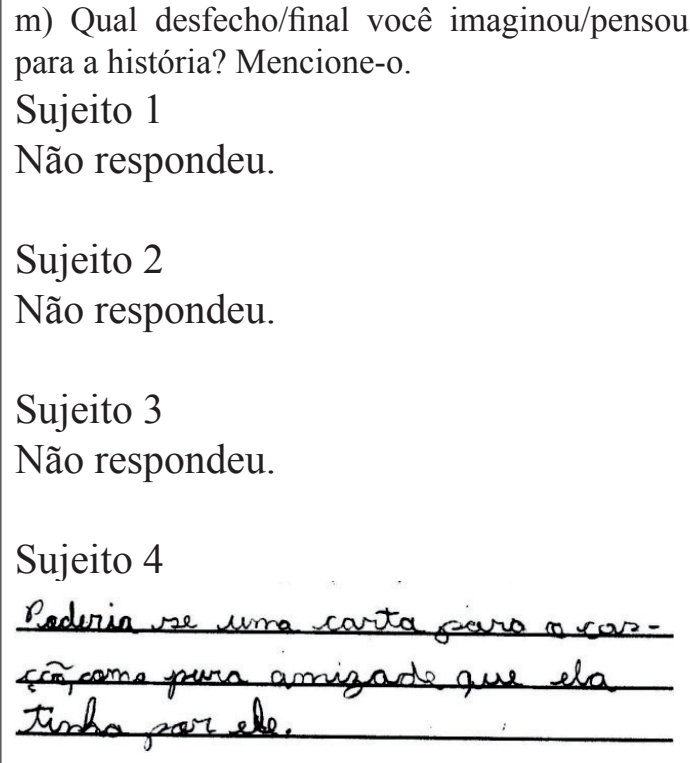 \\
\hline
\end{tabular}




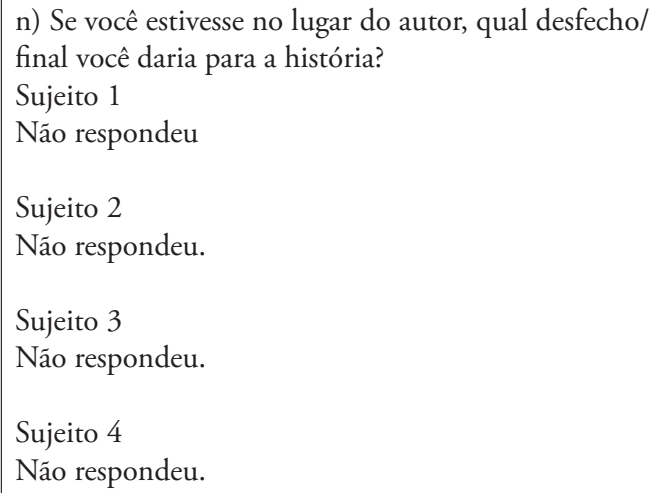

Caixa de texto 6 - Respostas sobre o enredo da HQ

Fonte: Elaboração própria a partir das questôes elaboradas e respostas dos alunos.

Ao analisarmos as respostas dos sujeitos sobre o enredo, constatamos que eles conseguiram registrar quem eram as personagens, quando e onde se passava a história e, mesmo com dificuldades, também registraram o conflito e o desfecho. Somente os sujeitos 3 e 4 conseguiram responder à pergunta " $m$ ", embora o sujeito 3 a tenha respondido na pergunta anterior, quando afirma: Eu pensei que era um segredo da Mônica (Sujeito 3); Poderia ser uma carta para o Cascáo, como para a amizade que ela tinha por ele (Sujeito 4). Isso demonstra, por parte dos demais participantes, pouca habilidade na antecipação de sentido, um dos requisitos básicos para a leitura. Já na pergunta "n", nenhum dos participantes conseguiu respondê-la.

Nas atividades posteriores, passamos a mediar os conceitos relativos às condições de produção, ao tema e ao enredo das HQs. O resultado do trabalho desenvolvido nesse módulo podemos verificar após a leitura de Cebolinha em: o forçudo (Figura 3), de Maurício de Sousa. Os sujeitos responderam na modalidade escrita da língua a perguntas sobre as condições de produção, do tema e do enredo da história, cujas respostas são exaradas nas Caixas de texto 7 e 8. 


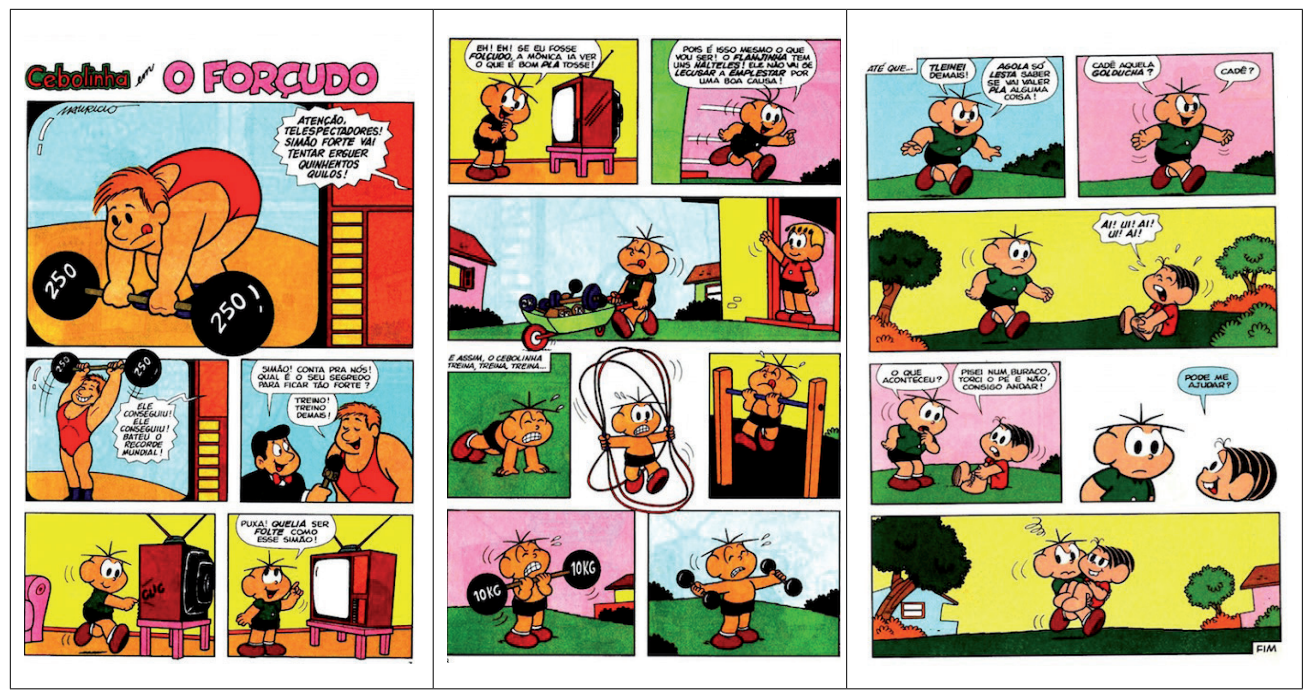

Figura 3 - História em quadrinhos Cebolinha em: o forçudo

Fonte: Almanaque da Mônica (2014, p. 7-9).

Ao analisarmos as respostas emitidas pelos sujeitos, percebemos que, mesmo já demostrando ter os conhecimentos desde a atividade inicial do Módulo I, a organização do pensamento na escrita apresentou uma pequena melhora, uma vez que as respostas estão mais claras e objetivas e melhor elaboradas (Caixa de texto 7). Isso demonstra a necessidade de um trabalho mais sistematizado com os conceitos e suas formas de avaliação de compreensão pela escrita. Somente o sujeito 4 grafou a resposta errada na questão de letra "b".

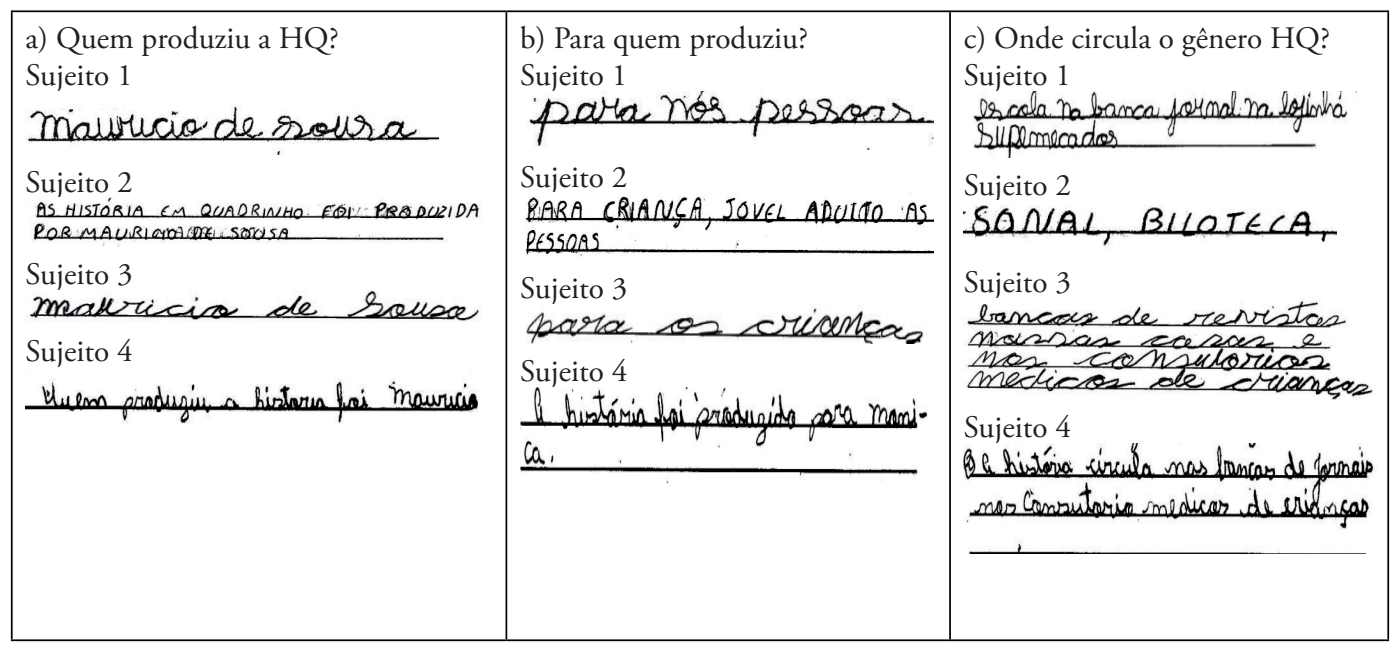

Caixa de texto 7 - Respostas sobre as condições de produção da HQ

Fonte: Elaboração própria a partir das questôes elaboradas e respostas dos alunos. 
Para a compreensão, é necessária uma leitura mais aprofundada. Assim sendo, nenhum dos sujeitos conseguiu abstraí-la. A temática abordou uma das possibilidades de uso da força, nesse caso, para o bem. A resposta força, grafada pelos sujeitos 1 e 2, considera apenas o assunto, o que evidencia a fase inicial de apropriação conceitual, já que depreender o assunto da história também significa ter depreendido parte do tema. Diante do exposto, salienta-se a necessidade de mais pesquisas e metodologias para que essa habilidade seja construída nos sujeitos. Já o sujeito 3 expressou ser a vaidade o tema da história, o que se configurou em um equívoco de compreensão. Para o sujeito 4, o tema é: a força do Simão, pois a personagem serviu de inspiração ao Cebolinha, não constituindo assim a temática da história (Caixa de texto 8).

d) Qual tema a história em quadrinhos abordou? Sujeito 1<smiles>CCCC(C)(C)OC</smiles>

Sujeito 2 FORCA

Sujeito 3

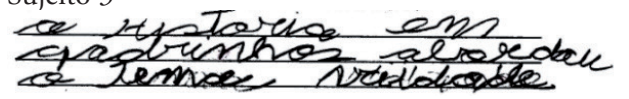

Sujeito 4

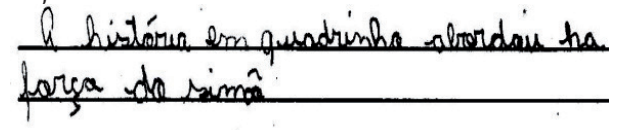

e) Qual é a finalidade do autor ao escrever sobre esse tema?

Sujeito 1

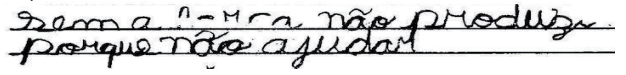

Sujeito 2

ESTREVER A EORDE

Sujeito 3

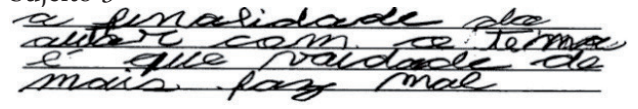

Sujeito 4

- C. finalidade da histónia, of para o ceblemba ficar fartes inemavem fuce tranda soors

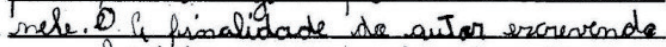
essa história é par a selselinha ficar
forte.

Caixa de Texto 8 - Respostas sobre o tema e a finalidade da HQ

Fonte: Elaboração própria a partir das questóes elaboradas e respostas dos alunos.

Os participantes também não compreenderam as possíveis finalidades do autor ao produzir a história com esse tema. Embora as respostas tenham sido diferentes das esperadas, confirmam a afirmativa do Cebolinha: Agola só lesta saber se vai valer pla alguma coisa!. Isso demostra que os sujeitos estão em processo de elaboração conceitual, ainda de forma incompleta. Ressaltamos que, além do entretenimento, há a finalidade educativa que, embora velada, apresenta-se justamente na quebra da expectativa, uma vez que o Cebolinha, ao usar a força para ajudar a Mônica, acaba rompendo a expectativa do leitor, apresentando um desfecho inesperado e com uma finalidade educativa para ser trabalhada com os leitores. 
f) Quem são as personagens?

Sujeito 1

as peronagens reporter falando pelo simá cepulenerá l manuca

Sujeito 2

OS PERSONAGENS NA HISTÓRIA SAO CEBOLNHA, SIMÃO, MÔNMCA, RERORTE,

ERANGINHA NAWUL. .

Sujeito 3

as persanagens sế. simá, reparte, celo-

limhar manuca e

franginga

Sujeito 4

Us farranagem bx̃ as, telespectadares, se celolinh reporter, simá \&a.manica.

h) Quando se passa a história?

Sujeito 1

a cebolinlna erta forte

Sujeito 2

AS HISTÓRIA EM QUADRINHES? A CEROLINHA PETOU OU IELEVISÃO

Sujeito 3

a scistóruce ne paspa

Sujeito 4

Chistória be parasa rnam lim de

j) Qual foi o conflito, o problema que aconteceu?

Sujeito 1 Uque a coundecell monica mancucale

Sujeito 2

AS HISTORIA $\mathrm{EM}$ QUADRINHO DO CEBOLNOHA GAREGOCIIU D CARINHO O PESADE

Sujeito 3

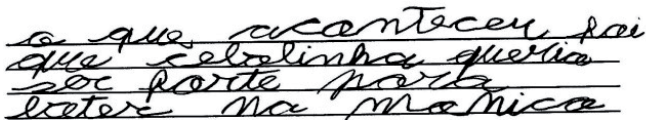

Sujeito 4

UPoblema fa que cebolinha, queris-s farte le só ajudar a minanica. g) Onde se passa a história?

Sujeito 1

Na cara celeodinliá na ty

lsta forl de cara celolinhá e monica

Sujeito 2

AS HISTÓRIA EM QUADRINHOS OS

REPORTE SALOU COM SIMÃO.

Sujeito 3

a Histária se paspa na TV, Na cana de cebrelinax \& Mo quintae

Sujeito 4

le história se parsia ria cara da abolinha, ma acadernia casa do colega dre celolinha, mum park.

i) O que aconteceu na história?

Sujeito 1

has histo tia lon quadrinho celrolmena lstarva jundor com monica. cebolmbá levolu a monica para casa deln

Sujeito 2

AS CEBOLINHA PEIGOU No cole can MÔNICA IE VOU PARA CASA

Sujeito 3

a que arcantecen na thistórcia fac ente celredimpar pulaven ser ina muen nuever

Sujeito 4

Ta hustária a abolinka queria ser

frorte come a simas?

k) Como o problema foi resolvido, qual foi o desfecho/final?

Sujeito 1

ile celoleminá lenamtar maníra

Sujeito 2

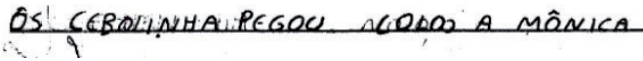
Sujeito 3

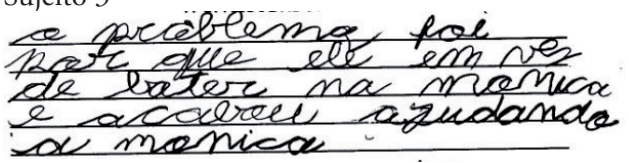

Sujeito 4

$\checkmark$ Poblema fai resalvido cain o.

selrolisiha acalrou afudanda a sranica 


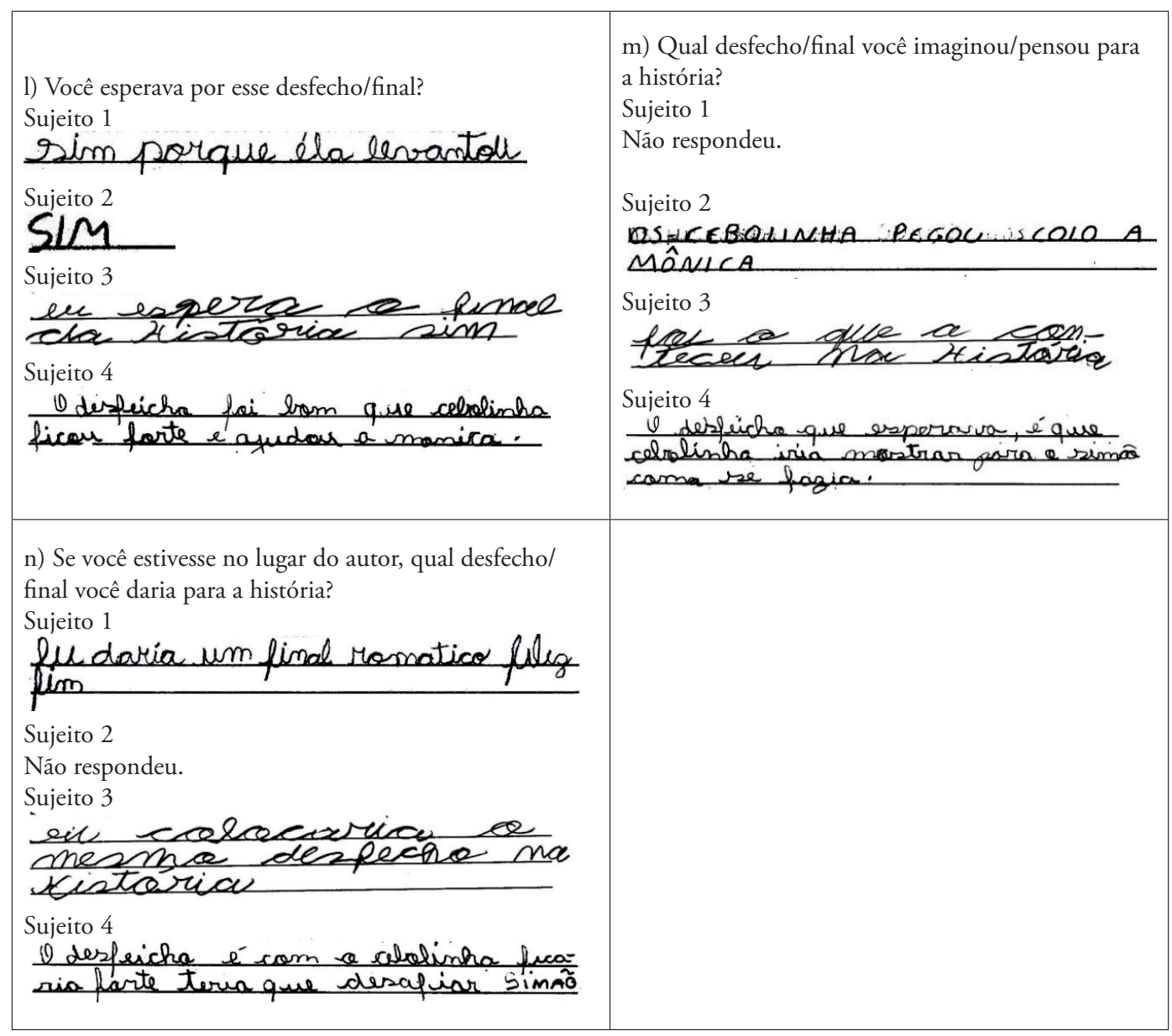

Caixa de texto 9 - Respostas sobre o enredo da HQ)

Fonte: Elaboração própria a partir das questôes elaboradas e respostas dos alunos.

A antecipação de sentido expressa na pergunta "m" passou a ser respondida, mesmo todos afirmando que já esperavam por esse desfecho. A pergunta " $\mathrm{n}$ " também foi respondida pelos sujeitos 1 e 4, com criatividade. Isso reafirma que as oportunidades das trocas de experiências são a base para a criatividade humana, inclusive entre indivíduos com deficiência intelectual. Assim, ao final do Módulo 1, afirmamos que houve melhoras na qualidade das respostas, na forma como os alunos as registraram, bem como na própria criatividade ao fazê-las. Os Quadros 1, 2 e 3 apresentam as sínteses dos resultados da pesquisa em relação ao conceitos científicos de tema, enredo e condições do produção do gênero proposto. 


\begin{tabular}{|l|l|l|l|l|}
\hline Conceitos do módulo I & Sujeito 1 & Sujeito 2 & Sujeito 3 & Sujeito 4 \\
\hline Autoria & {$\left[{ }^{* * *}\right]\left(^{* * *}\right)$} & {$\left[{ }^{* *}\right]\left(^{* * *}\right)$} & {$[\mathrm{f}]\left(^{* * *}\right)$} & {$\left[{ }^{* * *}\right]\left(^{* * *}\right)$} \\
\hline Meio do circulaçáo da HQ & {$\left[{ }^{* * *}\right]\left(^{* * *}\right)$} & {$\left[{ }^{* * *}\right]\left(^{* * *}\right)$} & {$[\mathrm{f}]\left(^{* * *}\right)$} & {$\left[{ }^{* * *}\right]\left(^{* * *}\right)$} \\
\hline A quem se destinam as HQs & {$\left[{ }^{*}\right]\left(^{* * *}\right)$} & {$\left[{ }^{* * *}\right]\left(^{* * *}\right)$} & {$[\mathrm{f}]\left(^{* * *}\right)$} & {$\left[{ }^{*}\right]\left(^{*}\right)$} \\
\hline
\end{tabular}

Quadro 1 - Síntese dos resultados da pesquisa em relação aos conceitos científicos da História em Quadrinhos

Fonte: Elaboração própria.

Legenda: * Conceito em processo inicial de elaboraçáo; ${ }^{* * *}$ conceito apropriado; conceitos apresentados pelos participantes antes da intervençăo [ ] e após a intervenção ( ); "f" - faltou a aula.

\begin{tabular}{|l|l|l|l|l|}
\hline Conceitos & Sujeito 1 & Sujeito 2 & Sujeito 3 & Sujeito 4 \\
\hline Temática da história & {$\left[*^{*}\right]\left(*^{*}\right)$} & {$\left[*^{*}\right]\left(^{*}\right)$} & {$[\mathrm{f}](-)$} & {$\left[*^{*}\right]\left(^{*}\right)$} \\
\hline Finalidade da história & {$[\mathrm{n}]\left({ }^{*}\right)$} & {$[\mathrm{n}]\left({ }^{*}\right)$} & {$[\mathrm{f}](*)$} & {$\left[{ }^{*}\right]\left(^{*}\right)$} \\
\hline
\end{tabular}

Quadro 2 - Síntese dos resultados em relação ao tema

Fonte: Elaboração própria.

Legenda: - Ausência do conceito; * Conceito em processo inicial de elaboração; conceitos apresentados pelos participantes antes da intervenção [ ] e após a intervenção ( ); "f" - faltou a aula; n não realizou a atividade.

\begin{tabular}{|c|c|c|c|c|}
\hline Conceitos & Sujeito 1 & Sujeito 2 & Sujeito 3 & Sujeito 4 \\
\hline Personagem & {$[* * *](* *)$} & {$[* * *](* * *)$} & {$[* * *](* * *)$} & {$[* * *](* * *)$} \\
\hline Tempo & {$[* * *](* * *)$} & {$[* * *](* * *)$} & {$[* * *] \quad(* * *)$} & {$[* * *](* * *)$} \\
\hline Espaço & {$[* * *](* * *)$} & {$[* * *](* * *)$} & {$[* * *](* * *)$} & {$[* * *](* * *)$} \\
\hline Clímax & {$\left[{ }^{*}\right]\left({ }^{* * *}\right)$} & {$\left[{ }^{*}\right]\left({ }^{* *}\right)$} & {$[*](* *)$} & {$[*](* *)$} \\
\hline Desfecho & {$[*](* * *)$} & {$[*](* * *)$} & {$[*](* * *)$} & {$[*](* * *)$} \\
\hline
\end{tabular}

Quadro 3 - Síntese dos resultados em relação aos elementos da narrativa

Fonte: Elaboração própria.

Legenda: * Conceito em processo inicial de elaboraçấo; ${ }^{* *}$ conceito em processo final de elaboração; ${ }^{* * *}$ conceito apropriado; conceitos apresentados pelos participantes antes da intervençáo [ ] e após a intervenção ( ). 


\section{CONSIDERaÇóES}

Organizar a mediação dos conceitos científicos presentes do gênero textual História em Quadrinhos, a partir da organização metodológica proposta por Dolz, Noverraz e Schneuwly (2004), mostrou-se muito profícua com os alunos diagnosticados com deficiência intelectual. A proposta de ensino permite que todos os conceitos relativos à compreensão e à interpretaçáo do gênero sejam contemplados. Não há restriçôes ao número de módulos ou de atividades, pois prima-se pela qualidade do ensino, podendo atender às especificidades do grupo pesquisado, ampliando, reduzindo ou diferenciando as atividades e os recursos sempre que forem necessários para que o trabalho de apropriaçáo dos conceitos eleitos seja efetivado adequadamente.

Em relação aos conceitos científicos trabalhados no Módulo I, podemos afirmar que os sujeitos participantes melhoraram o nível de leitura do gênero HQ, pois compreenderam as condiçôes de produção do gênero trabalhado, melhoraram a compreensão dos elementos da narrativa, assim como a forma de registrar suas respostas por meio da linguagem escrita.

Por sua vez, os conceitos que os sujeitos participantes náo apresentaram melhora significativa são: a compreensão do tema, a finalidade e o clímax. Esses resultados mostram que se requer a proposição e a busca de novas estratégias de mediação verbal e didático-pedagógica, pois esses conceitos são complexos e até mesmo as pessoas que não possuem deficiência apresentam dificuldade em sua abstração e generalização.

\section{REFERÊNCIAS}

AUADA, V. G. C. Apropriação de conceitos cientificos e processo de letramento em jovens e adultos com deficiência intelectual. 2015. 169 f. Dissertação (Mestrado em Educação) - Universidade Estadual de Maringá, Maringá, 2015.

BAKHTIN, M. Os gêneros do discurso. In: . Estética da criação verbal. São Paulo: Martins Fontes, 2000. p. 277-326.

BRASIL. Parâmetros curriculares nacionais: ensino médio: linguagem, códigos e suas tecnologias. 2000. Disponível em: <http://portal.mec.gov.br/seb/arquivos/pdf/14_24.pdf>. Acesso em: 20 jan. 2015.

CHARTIER, R. Formas e sentido. Cultura escrita: entre distinção e apropriaçẫo. Campinas: Mercado de Letras; Associação de Leitura do Brasil, 2003.

DOLZ, J.; NOVERRAZ, M.; SCHNEUWLY, B. Sequências didáticas para o oral e a escrita: apresentação de um procedimento. In: DOLZ, J.; SCHNEUWLY, B. Gêneros orais e escritos na escola. Campinas: Mercado das Letras, 2004. p. 95-128.

GÓES, M. C. R. de. Relaçôes entre desenvolvimento humano, deficiência e educação: contribuiçóes da abordagem histórico-cultural. In: OLIVEIRA, M. K.; SOUZA, D. T. R.; REGO, T. C. (Orgs.). Psicologia, educação e as temáticas da vida contemporânea. São Paulo: Moderna, 2002. p. 95-114.

MARCUSCHI, L. A. Produção textual, análise de gêneros e compreensão. São Paulo: Parábola, 2005.

PADILHA, A. M. L. Desenvolvimento Psíquico e elaboração conceitual por alunos com deficiência intelectual na educação escolar. Revista Brasileira de Educação Especial, Marília, v. 23, n. 1, p. 9-20, jan./mar., 2017. DOI: <http://dx.doi.org/10.1590/s1413-65382317000100002>.

SCHALOCK, R. L. et al. Intelectual disability: definition, classification and systems of support. Washington: AAIDD, 2010. 
SHIMAZAKI, E. M. Letramento em jovens e adultos com deficiência mental. 2006. 188 f. Tese (Doutorado em Educação) - Faculdade de Educação, Universidade de São Paulo, São Paulo, 2006.

SOUSA, M. Almanaque histórias de três páginas turma da Mônica. São Paulo: Panini, n. 9, 2014.

TRIPP, D. Pesquisa-ação: uma introdução metodológica. Educação e Pesquisa, São Paulo, v. 31, n. 3, p. 443-466, set./dez. 2005.

VYGOTSKY, L. S. Pensamento e linguagem. São Paulo: Martins Fontes, 1987.

VYGOTSKY, L. S. A construção do pensamento e da linguagem. Tradução Paulo Bezerra. São Paulo: Martins Fontes, 2000. 